\title{
Retrospective Analysis of Eculizumab in Patients with Acetylcholine Receptor Antibody-Negative Myasthenia Gravis: A Case Series
}

\author{
Sorabh Datta ${ }^{1}$, Shivangi Singh and Raghav Govindarajan* \\ University of Missouri Health Care, Columbia, MO, USA
}

\begin{abstract}
.
Background: The role of the complement cascade in acetylcholine receptor antibody-negative (AChR-) myasthenia gravis (MG) is unclear.

Objective: To assess the efficacy and tolerability of eculizumab (terminal complement inhibitor) in patients with AChRMG.

Methods: Retrospective chart review of data from six patients treated for 12 months with eculizumab for treatment-refractory, AChR- (by radioimmunoassay) generalized MG (gMG). The eculizumab dose was $900 \mathrm{mg} /$ week for 4 weeks then $1200 \mathrm{mg}$ every 2 weeks. Outcome measures were Myasthenia Gravis-Activities of Daily Living (MG-ADL) scores, number of exacerbations, and qualitative physical assessments based on selected items of the Quantitative Myasthenia Gravis evaluation (ptosis, double vision, eye closure, duration of ability to stretch out limbs).

Results: All patients were female (mean age, 50.8 years). In the 12 months before eculizumab initiation, all measures were relatively stable. After its initiation, clinically meaningful reductions ( $\geq 2$ points) in total MG-ADL scores were observed before or at 5 months and were maintained to Month 12 in all patients; mean (standard deviation [SD]) scores were $11.3(0.9)$ and $5.0(0.9)$, respectively. There was also a reduction in the mean (SD) number of exacerbations per patient, from 2.8 (1.2) to $0.3(0.5)$ in the 12 months before and after eculizumab initiation, respectively. Physical assessment ratings were improved in all patients. Adverse events were reported in four patients, but all were mild and none were treatment-related.

Conclusions: This small retrospective analysis provides preliminary evidence for the efficacy of eculizumab in treatmentrefractory gMG that was AChR- according to radioimmunoassay. Larger, more robust studies are warranted to evaluate this further.
\end{abstract}

Keywords: Myasthenia gravis, ACh receptors, neuromuscular junction, complement inactivating agents, activities of daily living, corticosteroids

\footnotetext{
${ }^{1}$ Current affiliation: Baptist Health-University of Arkansas for Medical Sciences, North Little Rock, AR, USA.

*Correspondence to: Dr R. Govindarajan, Department of Neurology, University of Missouri, 1 Hospital Drive, Columbia, MO 65212, USA. Tel.: +1 573882 1515; E-mail: govindarajanr@ health.missouri.edu.
}

\section{INTRODUCTION}

Myasthenia gravis (MG) is an autoimmune disorder caused by autoantibodies that target proteins at the neuromuscular junction (NMJ) [1-3]. As a consequence, synaptic transmission at the NMJ is disrupted and the disease manifests as fluctuating weakness and 
easy fatigability of the skeletal muscles [2-4]. There are different subtypes of MG, classified on the basis of the clinical phenotype and the type of autoantibodies involved in the disease process [5]. Most patients (75-80\%) have antibodies against the acetylcholine receptor (AChR) [2-4, 6]; historically, AChR antibody-positive (AChR+) MG has been referred to as 'seropositive'. Anti-AChR antibodies mainly comprise the immunoglobulin (Ig)G1 and IgG3 subtypes, and their binding leads to a reduction in AChR numbers and function via mechanisms that include complement-mediated postsynaptic membrane damage $[7,8]$.

More recently, other antigenic targets have been discovered to be involved in the development of MG. These include muscle-specific tyrosine kinase (MuSK), low-density lipoprotein receptor-related protein 4 (LRP4), and cortactin protein [6, 9-12]. MuSK antibodies are detected in 30-40\% and LRP4 antibodies in 7-33\% of patients with AChR antibodynegative (AChR-) MG [3, 13]; MG in those who lack antibodies against both AChR and MuSK is often referred to as 'double seronegative' [13]. Cortactin antibodies have been detected in $\sim 20 \%$ of patients with double-seronegative MG [13].

Complement activation plays an important role in the pathogenesis of $\mathrm{AChR}+\mathrm{MG}$ via the formation of membrane attack complexes (MACs) - lipophilic proteins that damage cell membranes $[14,15]$. In experimental autoimmune MG (an animal model induced by passive transfer of AChR antibodies), deficiencies in specific complement proteins or treatment with complement inhibitors prevents disease induction and/or reverses its progression [15, 16]. In patients with $\mathrm{AChR}+\mathrm{MG}$, complement proteins and MACs have been found at the NMJ $[15,16]$. Most recently, the terminal complement inhibitor eculizumab was shown to be effective in patients with $\mathrm{AChR}+$ refractory generalized MG (gMG) in a Phase 3, randomized, double-blind, placebocontrolled study (REGAIN), leading to its approval in the USA (AChR+gMG) [17], Europe (treatmentrefractory AChR+gMG) [18], and Japan (patients with gMG whose symptoms are difficult to control with high-dose intravenous immunoglobulin therapy or plasmapheresis) [19]. Eculizumab is a recombinant humanized monoclonal antibody that binds to the C5 complement protein, preventing its cleavage into C5a and C5b and ultimately blocking the C5b-9 MAC [20, 21]. Despite its efficacy in AChR+gMG, there is a lack of information on its effects in patients who are seronegative for anti-AChR antibodies. Here, we describe six patients with treatment-refractory AChR-gMG treated with eculizumab for 12 months.

\section{METHODS}

This was a retrospective chart review of data from six patients with $\mathrm{gMG}$ treated for $\geq 3$ years in the Neurology Clinic of the University of Missouri, Columbia, USA, between December 2016 and January 2019. Patients were eligible for inclusion if they were: $\geq 18$ years old; diagnosed with $\mathrm{gMG}$ that was refractory to conventional treatments; seronegative for AChR antibodies (radioimmunoassay [RIA], Mayo Clinic Laboratories, Rochester, MN, USA; Test ID: MGA1); treated with eculizumab for $\geq 12$ months; and vaccinated against Neisseria meningitidis before initiating eculizumab, as recommended in the prescribing information [17]. Refractory MG was defined as treatment with $\geq 2$ immunosuppressant therapies (ISTs) for $\geq 12$ months without symptom control, or $\geq 1$ IST for $\geq 12$ months with intravenous immunoglobulin or plasma exchange given $\geq 4$ times/year without symptom control. Patient data were collected for 12 months after initiation of eculizumab.

Eculizumab was administered at an induction dose of $900 \mathrm{mg}$ per week for 4 weeks (at Weeks 0, 1, 2, and 3 ), then at $1200 \mathrm{mg}$ at Week 4, followed by $1200 \mathrm{mg}$ every 2 weeks thereafter, as per the prescribing information for the product [17].

The following parameters were evaluated in the 12 months before and after eculizumab initiation: monthly Myasthenia Gravis-Activities of Daily Living (MG-ADL) scores [22]; number of exacerbations; qualitative physical assessments of selected items from the Quantitative Myasthenia Gravis (QMG) evaluation [23] (degree of ptosis, double vision, and eye closure, and the duration of ability to stretch out arms and legs, classified as none, mild, moderate, or severe); and respiratory function, using the single-breath count test (SBCT) [24]. The number of exacerbations was based on patient self-reports and/or episodes of hospitalization for MG-related symptoms. Final diagnosis of an MG exacerbation was at the discretion of a board-certified neurologist on call. The neurologist diagnosed an exacerbation based on the presence of dysphagia, acute respiratory failure, or major functional disability precluding physical activity and other objective exam findings [25]. The SBCT was performed by asking patients to take a deep breath and count as far as possible in their 
Table 1

Baseline demographic and clinical characteristics of patients included in the analysis

\begin{tabular}{|c|c|c|c|c|c|c|c|}
\hline Patient & Sex & $\begin{array}{l}\text { Age } \\
\text { (years) }\end{array}$ & $\begin{array}{c}\text { Year of } \\
\text { diagnosis }\end{array}$ & $\begin{array}{l}\text { Date of eculizumab } \\
\text { initiation }\end{array}$ & $\begin{array}{l}\text { MGFA class before } \\
\text { eculizumab initiation }\end{array}$ & Thymectomy $^{a}$ & Medication in previous 12 months \\
\hline 1 & $\mathrm{~F}$ & 57 & 2015 & June 2018 & IIa & $\mathrm{Y}(2$ years ago $)$ & $\begin{array}{l}\text { Prednisone ( } 50 \mathrm{mg} / \text { day }) \\
\text { pyridostigmine }(60 \mathrm{mg} \text { TID), } \\
\text { IVIG (1 g/kg q4w), } \\
\text { mycophenolate (1000 mg BID) }\end{array}$ \\
\hline 2 & $\mathrm{~F}$ & 50 & 2016 & August 2018 & IIIa & $\mathrm{Y}(5$ years ago $)$ & $\begin{array}{l}\text { Prednisone ( } 40 \mathrm{mg} / \text { day), } \\
\text { pyridostigmine }(60 \mathrm{mg} \text { TID), } \\
\text { IVIG }(1 \mathrm{~g} / \mathrm{kg} \mathrm{q} 4 \mathrm{w}) \text {, azathioprine } \\
\text { (100 mg BID) }\end{array}$ \\
\hline 3 & $\mathrm{~F}$ & 45 & 2015 & November 2018 & $\mathrm{IIb}$ & Y (6 years ago $)$ & $\begin{array}{l}\text { IVIG ( } 1 \mathrm{~g} / \mathrm{kg} \mathrm{q} 4 \mathrm{w}), \text { pyridostigmine } \\
\text { (60 mg QID), prednisone } \\
\text { (30 mg/day) }\end{array}$ \\
\hline 4 & $\mathrm{~F}$ & 59 & 2015 & September 2018 & IIa & $\mathrm{N}$ & $\begin{array}{l}\text { Prednisone }(50 \mathrm{mg} / \text { day }), \\
\text { mycophenolate (1000 mg BID), } \\
\text { pyridostigmine ( } 60 \mathrm{mg} \text { TID) }\end{array}$ \\
\hline 5 & $\mathrm{~F}$ & 34 & 2016 & September 2018 & IIIa & $\mathrm{N}$ & $\begin{array}{l}\text { PLEX ( } 5 \text { courses } \mathrm{q} 4 \mathrm{w}) \\
\text { pyridostigmine }(60 \mathrm{mg} \text { TID) } \\
\text { prednisone }(50 \mathrm{mg} / \mathrm{day})\end{array}$ \\
\hline 6 & $\mathrm{~F}$ & 60 & 2015 & July 2018 & IIIb & $\mathrm{Y}(4$ years ago $)$ & $\begin{array}{l}\text { PLEX ( } 5 \text { courses } q 4 \mathrm{w}) \text {, prednisone } \\
\text { (40 mg/day), pyridostigmine } \\
\text { (60 } \mathrm{mg} \text { TID) }\end{array}$ \\
\hline
\end{tabular}

a Patient 1 had no abnormal histopathologic findings; Patients 2, 3, and 6 had thymus hyperplasia. BID, twice daily; F, female; IVIG, intravenous immunoglobulin; MGFA, Myasthenia Gravis Foundation of America; N, no; PLEX, plasma exchange; q4w, every 4 weeks; QID, four times daily; TID, three times daily; Y, yes.

normal voice at an approximate rate of 2 counts per second.

The University of Missouri Institutional Review Board approved the study (Approval No. 2016501 $\mathrm{MU})$, which was conducted according to the university's guidelines for retrospective studies.

\section{RESULTS}

Demographic and clinical characteristics of the six patients whose data were included in the study are summarized in Table 1. All were female and the mean (standard deviation [SD]) age was 50.8 (10.1) years. Myasthenia Gravis Foundation of America (MGFA) class was IIa $(n=2)$, IIb $(n=1)$, IIIa $(n=2)$, and IIIb $(n=1)$. Four patients had previously undergone thymectomy, one patient in the previous 2 years, one in the previous 4 years, and two in the previous 5 years. All patients had been treated with pyridostigmine and prednisone in the past 12 months. Other treatments received in the past 12 months were azathioprine, mycophenolate, intravenous immunoglobulin, and plasma exchange (see Table 1 for more details).

On chart review, documentation of gMG diagnosis was confirmed for all six patients. All patients had an MG-ADL score $\geq 6$ before eculizumab initiation. In each patient a decremental response and abnormal jit- ter had been observed in repetitive nerve stimulation and single-fiber electromyography studies, respectively, which were conducted prior to referral to the authors' clinic. According to antibody testing, which was conducted at diagnosis, then 6 and 12 months later, all six patients were seronegative for $\mathrm{AChR}$ antibodies (as per the inclusion criteria). Three patients were also tested for MuSK antibodies (RIA, Mayo Clinic Laboratories, Rochester, MN, USA; Test ID: MUSK) and LRP4 antibodies (immunofluorescence assay, Athena Diagnostics, Marlborough, MA, USA; Test ID: 1483), and were negative for both.

\section{Efficacy}

In the 12-month period before eculizumab initiation, MG-ADL scores were relatively stable in all patients. After eculizumab was started, there was a gradual reduction in MG-ADL total scores up to Month 12 in all patients (Fig. 1); mean (SD) scores were $11.3(0.9)$ at Month 0 and and $5.0(0.9)$ at Month 12. Clinically meaningful reductions ( $\geq 2$ points) in total MG-ADL scores were observed before or at 5 months and were maintained to Month 12 in all patients. In the 12 months before starting eculizumab, patients had 2 to 5 exacerbations (mean [SD] 2.8 [1.2]); in the 6-month period immediately before initiation, the number of exacerbations was the same or 


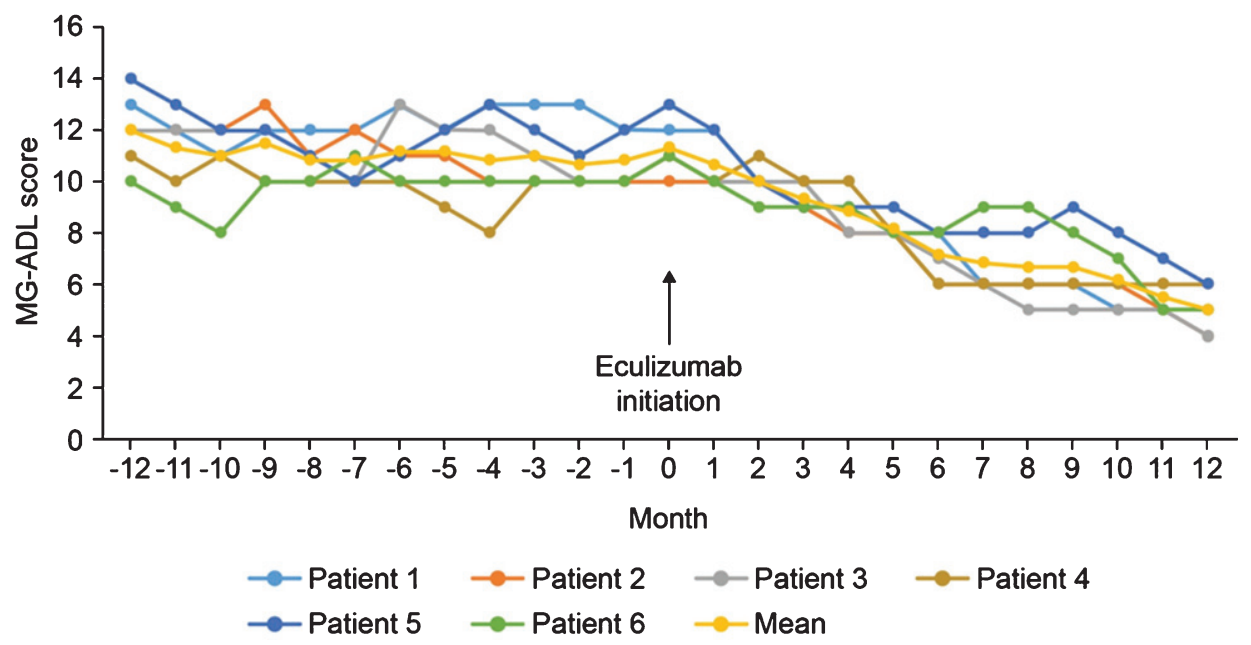

Fig. 1. MG-ADL total scores before and during 12 months' treatment with eculizumab. MG-ADL, Myasthenia Gravis-Activities of Daily Living.

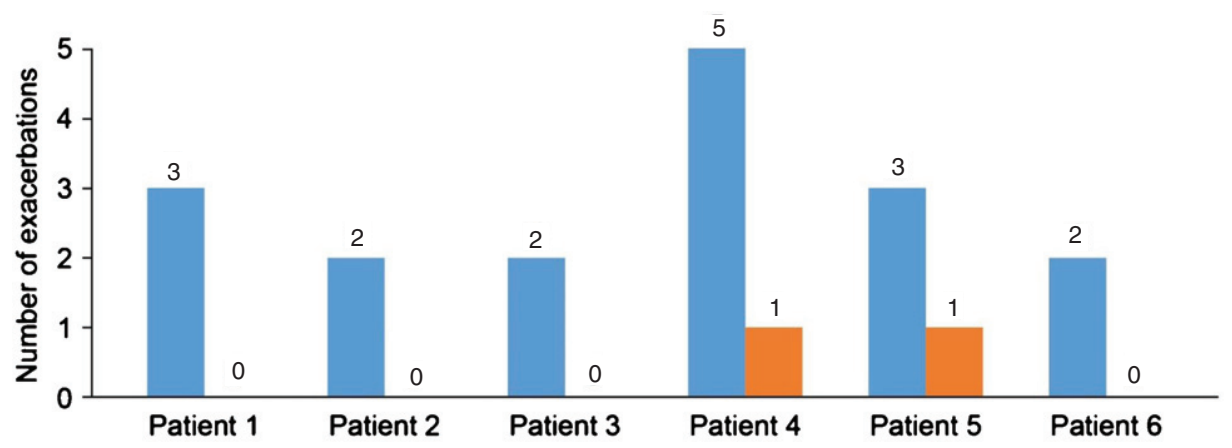

In 12 months before eculizumab initiation

In 12 months after eculizumab initiation

Fig. 2. Number of exacerbations in the 12 months before and after starting eculizumab.

higher than in the 12- to 6-month period before initiation in all patients (Supplementary Figure 1). After initiation of eculizumab, there was a reduction in the number of exacerbations in all patients (Fig. 2); the mean (SD) number of exacerbations in the 12-month follow-up period was $0.3(0.5)$. All patients had at least two exacerbations in the 12 months before eculizumab initiation; in the 12-month follow-up period, four patients had no exacerbations. Furthermore, all patients were able to reduce their steroid dose and discontinue at least one of their previous medications for gMG after starting eculizumab (Fig. 3). In three of the six patients, MGFA class did not change during the 12-month follow-up period; in the remaining patients, it changed from IIIa to IIa (two patients) and from IIIb to IIb (one patient).

With regard to the physical assessments, the severity of ptosis, double vision, eye closure, and limb stretching was relatively stable in the 12 months before eculizumab initiation, and improved during treatment, with most patients maintaining or achieving a classification of 'none' or 'mild' (Fig. 4). For the SBCT, scores were also stable before eculizumab initiation and increased (improved) in all patients during treatment (Fig. 5); mean (SD) scores before and at 12 months after starting eculizumab were $31.2(3.7) \mathrm{s}$ and 49.8 (4.1) s, respectively.

None of the patients in the study had a myasthenic crisis in the 12 months before or after eculizumab initiation.

\section{Safety}

Four patients had adverse events during eculizumab treatment. One patient had otitis media, upper respiratory infection, and post-infusion 


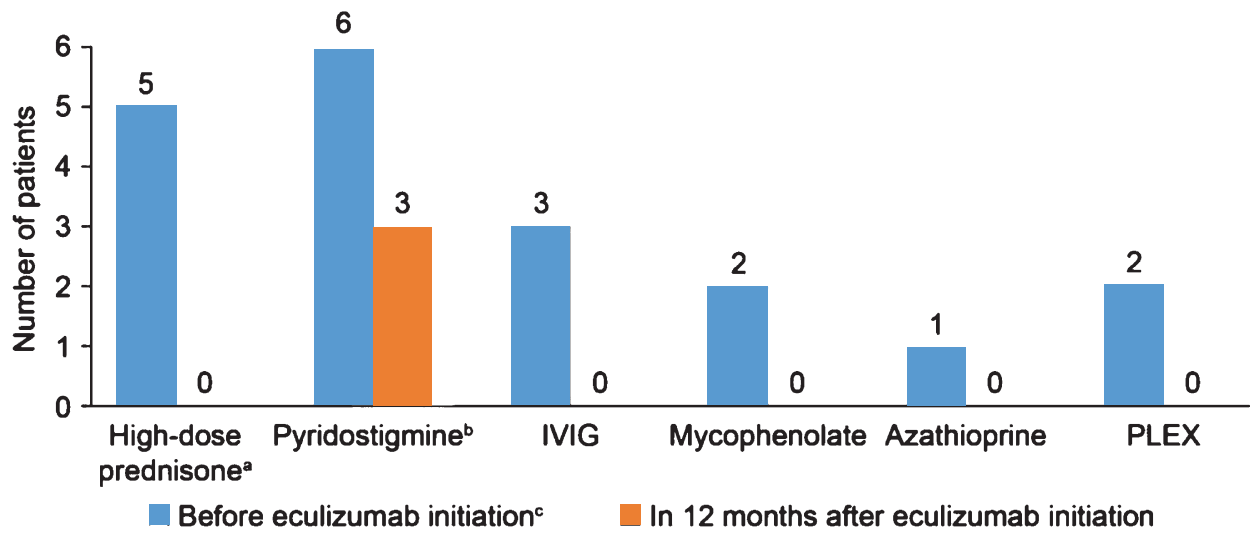

Fig. 3. Changes in generalized myasthenia gravis medication after starting eculizumab. ${ }^{\mathrm{a}} 12$ months after starting eculizumab, three patients had their daily prednisone doses reduced from $50 \mathrm{mg}$ to $10 \mathrm{mg}, 15 \mathrm{mg}$ and $20 \mathrm{mg}$, respectively, two patients had their dose reduced from $40 \mathrm{mg}$ to $10 \mathrm{mg}$ (the sixth patient also had her dose reduced, from $30 \mathrm{mg}$ to $10 \mathrm{mg}$ ); ${ }^{\text {b }} \mathrm{In}$ the three patients who continued pyridostigmine treatment after eculizumab initiation, two had their dose reduced from $60 \mathrm{mg}$ TID to $30 \mathrm{mg}$ TID and one had her dose reduced from $60 \mathrm{mg}$ QID to $60 \mathrm{mg}$ TID; ${ }^{\mathrm{c}}$ Further details of doses can be found in Table 1. IVIG, intravenous immunoglobulin; PLEX, plasma exchange; QID, four times daily; TID, three times daily.

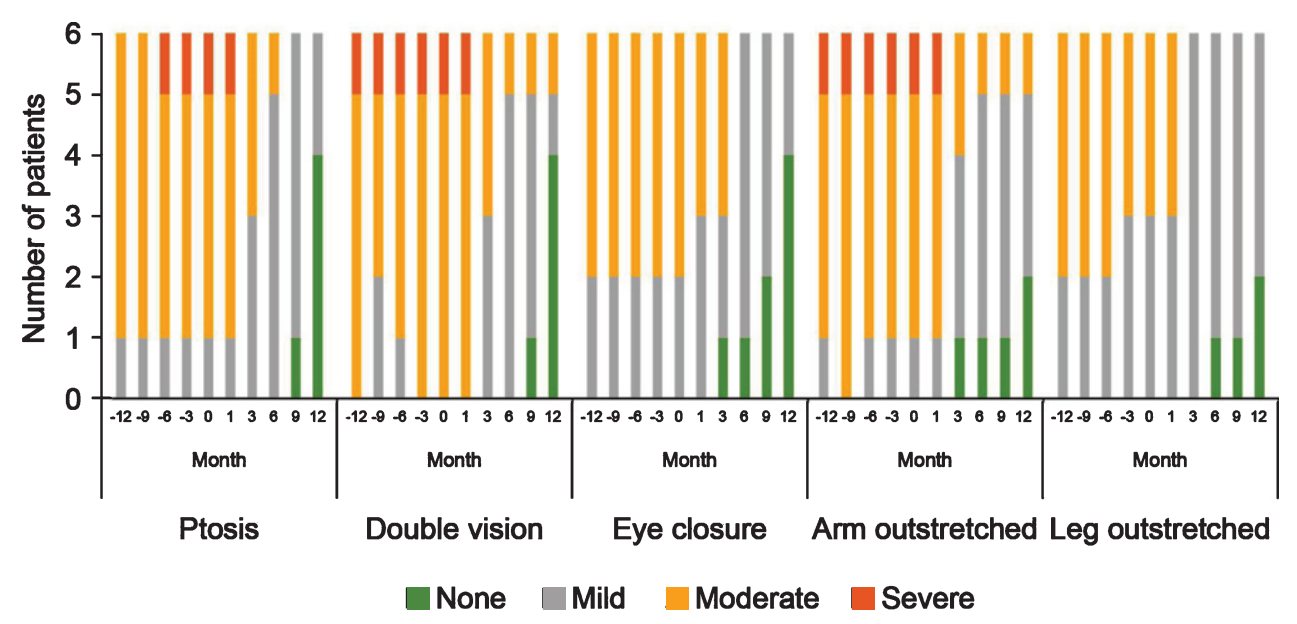

Fig. 4. Changes in physical assessments during treatment with eculizumab. Physical parameters were based on a qualitative assessment of selected items from the QMG evaluation and classified as mild, moderate or severe [23]. QMG, Quantitative Myasthenia Gravis.

headache, one patient had elevated aspartate transaminase and alanine transaminase levels, one patient had an upper respiratory infection, headache, and myalgias, and one patient had upper respiratory infection and headache. None of the events were considered related to eculizumab, all were mild in severity and no changes were made to the eculizumab treatment schedule as a result. The headaches were relieved by paracetamol and all other adverse events resolved without treatment. The case of elevated liver enzymes was not associated with any clinical symptoms.

\section{DISCUSSION}

The results of this retrospective chart review suggest that eculizumab may be effective in managing treatment-refractory gMG that is $\mathrm{AChR}$-according to RIA. This is an important observation, as up to $25 \%$ of patients with MG lack detectable antibodies against the AChR (when conventional immunoprecipitation assays are used) and treatment options are limited for these patients once their disease becomes refractory. Before eculizumab was started, patients' MG-ADL total scores were relatively stable and after its initia- 

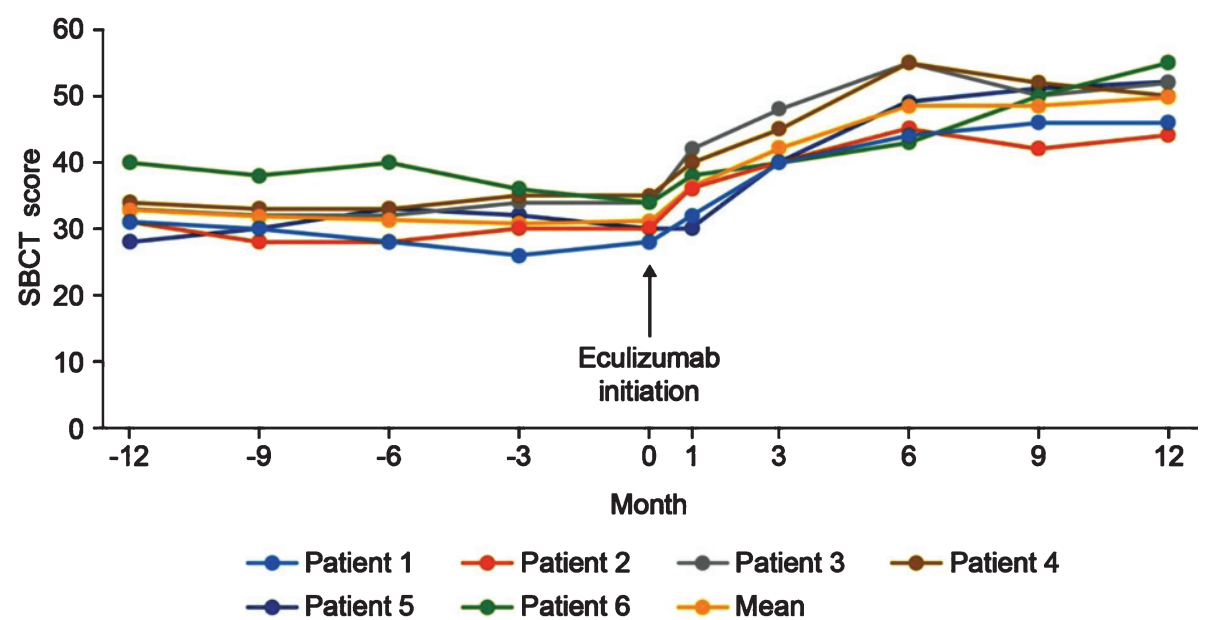

Fig. 5. SBCT scores in the 12 months before and after eculizumab administration. SBCT, single breath count test.

tion, there was a steady decline in each patient's total score up to study end (12 months after eculizumab initiation), with a magnitude of decrease $\geq 2$ points (the threshold for a clinically relevant change [26]) in all patients. All patients also experienced a reduction in the number of $\mathrm{MG}$ exacerbations, with four being exacerbation-free after eculizumab initiation. In each patient, the number of exacerbations in the 6 months before initiation was the same as, or higher than in the period 12 to 6 months before initiation, indicating that this parameter was not declining before eculizumab initiation. All patients were able to stop taking some of their existing medications completely and reduce their steroid dose after starting eculizumab. Once again, these are important clinical observations in view of the potential impact of exacerbations in gMG [27] and the burden of side effects of anticholinergics and ISTs [28].

The efficacy of eculizumab in $\mathrm{AChR}+\mathrm{gMG}$ is already established based on the results of the REGAIN study, which demonstrated a greater reduction in the MG-ADL total score and a lower exacerbation rate with eculizumab versus placebo [29]. These results confirm the significant role of the classic complement pathway in the pathogenesis of this MG subtype. The pathophysiology involves activation of the MAC by the AChR antigen-antibody immunocomplex, leading to destruction of AChRs at the NMJ via activation of the complement cascade [30, 31], which ultimately causes myasthenic symptoms [8]. Although AChR-MG is classified as a separate subtype of MG, there is accumulating evidence that it has many similarities with AChR+MG in terms of clinical characteristics and treatment response, e.g. acetylcholinesterase inhibitors and ISTs can be effective in AChR-MG [32]. AChR+ and AChR-MG also share pathophysiological features. In a study that evaluated pathologic thymus samples, patients with $\mathrm{AChR}+\mathrm{MG}$ had increased areas of perivascular lymph node-type infiltrates compared with controls, as expected, but this increase was also observed in $75 \%$ of patients with AChRand MuSK-MG, again highlighting commonalities between seropositive and seronegative MG [33].

It is now known that the assays most commonly used to measure anti-AChR autoantibodies (i.e. enzyme-linked immunosorbent assay [ELISA] and RIA) sometimes give false negative results as they are not sufficiently sensitive [34, 35]. Indeed, it has been shown using immunofluorescence staining that there are low-affinity AChR antibodies present in approximately $70 \%$ of patients who test seronegative using conventional assays [32]. It has therefore been recommended that cell-based assays, rather than ELISA or RIA, should be used in the assessment of patients with AChR-MG [32, 35-37]; however, cell-based assays are not widely available and/or reimbursed.

The anti-AChR antibodies detected using more sensitive assays had a low affinity for AChRs expressed in solution, but a high affinity for densely clustered AChRs as would be found on the cell surface at the NMJ [32]. These antibodies were predominantly IgG1. Sera from some patients with AChR-MG have been shown to be capable of causing deposition of complement $\mathrm{C} 3 \mathrm{~b}$ on clustered AChRexpressing cells in vitro [32]. The results suggest that low-affinity anti-AChR antibodies have the poten- 
tial to activate complement $\mathrm{C} 3 \mathrm{~b}$ deposition at the NMJ [38]. These observations support the importance of the role of IgG1 autoantibodies and the complement cascade in the pathogenesis of MG and explain similarities in the clinical features of patients with $\mathrm{AChR}+\mathrm{MG}$ and 'AChR-' MG (as defined by conventional assays) [38]. Additional evidence for the role of the complement cascade in AChR- MG comes from studies showing complement fixation on medullary epithelium and myoid cells in the thymic tissue of these patients [33], and reduced AChRs, along with complement deposition, at the endplates of muscle biopsies [39]. More recently, it was shown that MAC and the complement component 1q could be detected at the motor endplate in muscle biopsies from 'triple-seronegative' patients (i.e. those with no antibodies to AChR, MuSK, or LRP4 according to immunoassays) with treatment-refractory MG [40]. It has also been shown that there is a direct correlation between the degree of binding of both IgG1 and $\mathrm{C} 3 \mathrm{~b}$ complement protein and the decremental response seen on single-fiber electromyography in seronegative MG [38]. Collectively, these converging lines of evidence strongly suggest that antibodies with high affinity for clustered AChRs are pathogenic and indicate that the complement pathway plays a crucial role in pathogenesis and symptom development in patients with AChR-MG $[37,38]$. In the current study, patients' AChR-status was based on RIA only, so it is possible that some would have tested positive had more sensitive assays been used. Nevertheless, the results show that in a clinical setting in which a widely used assay showed patients to be AChR-, eculizumab was associated with clinical improvements in treatment-refractory gMG. Only three patients in the current study were tested for antibodies against MuSK and LRP4; in any future study, a full antibody profile would be informative, particularly as eculizumab is unlikely to be effective in anti-MuSK antibody-positive MG, which does not appear to involve complement activation [41]. None of the patients in the current study had a clinical profile associated with anti-MuSK antibodypositive MG, consistent with the positive response to eculizumab in all patients.

International consensus guidance on the treatment of MG advocates the goal of 'minimal manifestation status' (no symptoms or functional limitations from MG, but allowing for some motor weakness on examination) with medication side effects of grade $\leq 1$ [42]. Eculizumab was well tolerated in the current study, with a safety profile consistent with that observed in previous clinical studies in AChR+MG [29], paroxysmal nocturnal hemoglobinuria [43], and atypical hemolytic uremic syndrome $[44,45]$. The most common side effect of eculizumab is headache, which has been reported to occur in $\geq 10 \%$ of patients receiving eculizumab, mainly in the initial stages of treatment [18]. Meningococcal infection is a serious potential consequence of eculizumab treatment and patients must therefore receive meningococcal vaccines at least 2 weeks before the start of the treatment. Patients who have not previously received vaccination should also receive 2 weeks of prophylactic antibiotics when they are vaccinated $[17,18]$.

Eculizumab offers a rapid onset of action, which is an advantage over ISTs as they may require administration for several months to provide any significant clinical benefits. In this study eculizumab was administered "off-label" in patients who had very limited treatment options and who had received authorization from their medical insurance companies for the off-label treatment. Given the relatively high cost of eculizumab, further research is needed to assess its cost-effectiveness for treating refractory seropositive/seronegative gMG [46].

The limitations of the current study include its retrospective design, lack of control group, and small number of patients. As such, the potential benefit of eculizumab in AChR- MG will require further evaluation in a larger, controlled study with a more robust design. More frequent patient monitoring in the weeks immediately before and after initiation of eculizumab would also be informative. Nevertheless, the current study used standardized data-collection methods and a validated tool (MG-ADL) to assess outcomes, providing results that are credible and valuable to physicians who manage patients with treatment-refractory AChR-MG.

\section{CONCLUSIONS}

To the best of our knowledge, this is the first case series to evaluate the efficacy of eculizumab in patients with MG that was determined to be AChR- according to RIA. In this study we identified and treated AChR- patients who were refractory to the conventional therapies, and provided preliminary evidence that eculizumab may be effective in this subgroup of patients. These findings add to the limited data on AChR-MG in the literature. Hopefully the results of our small retrospective analysis might be beneficial to future research studies and should 
stimulate further research to explore the effects of eculizumab in patients with AChR- MG, as identified using conventional immunoprecipitation assays. It would also be interesting to evaluate the efficacy of eculizumab in patients with AChR-MG determined using cell-based assays.

\section{ACKNOWLEDGMENTS}

Editorial support was provided by Dr Nicky French of Anthemis Consulting Ltd, funded by Alexion Pharmaceuticals, Inc. Alexion Pharmaceuticals provided a medical-accuracy review of the final manuscript.

\section{CONFLICT OF INTEREST}

Sorabh Datta and Shivangi Singh have no conflicts of interest; Raghav Govindarajan serves on the advisory boards of Alexion Pharmaceuticals, argenx Pharmaceuticals, Mitsubishi Tanabe Pharmaceuticals, and Catalyst Pharmaceuticals, and has received research support from Alexion Pharmaceuticals, Ra Pharmaceuticals, Strongbridge Pharmaceuticals, The American Academy of Neurology, AMARC Enterprises/Poly-MVA, Dysimmune Foundation and InfuCare. He has received speaker's honoraria from Alexion Pharmaceuticals, Mitsubishi Tanabe Pharmaceuticals, Catalyst Pharmaceuticals, and Muscular Dystrophy Association, and publication honorarium from Springer Publishing, USA.

\section{SUPPLEMENTARY MATERIAL}

The supplementary material is available in the electronic version of this article: https://dx. doi.org/10.3233/JND-190464.

\section{REFERENCES}

[1] Berrih-Aknin S, Frenkian-Cuvelier M, Eymard B. Diagnostic and clinical classification of autoimmune myasthenia gravis. J Autoimmun. 2014;48-49:143-8. [PubMed: 24530233].

[2] Gilhus NE. Myasthenia gravis. $N$ Engl J Med. 2016;375(26):2570-81. [PubMed: 28029925].

[3] Gilhus NE, Skeie GO, Romi F, Lazaridis K, Zisimopoulou P, Tzartos S. Myasthenia gravis - autoantibody characteristics and their implications for therapy. Nat Rev Neurol. 2016;12(5):259-68. [PubMed: 27103470].

[4] Yi JS, Guptill JT, Stathopoulos P, Nowak RJ, O'Connor KC. $\mathrm{B}$ cells in the pathophysiology of myasthenia gravis. Muscle Nerve. 2018;57(2):172-84. [PubMed: 28940642].

[5] Gilhus NE, Verschuuren JJ. Myasthenia gravis: Subgroup classification and therapeutic strategies. Lancet Neurol. 2015;14(10):1023-36. [PubMed: 26376969].
[6] Gilhus NE, Tzartos S, Evoli A, Palace J, Burns TM, Verschuuren J. Myasthenia gravis. Nat Rev Dis Primers. 2019;5(1):30. [PubMed: 31048702].

[7] Binks S, Vincent A, Palace J. Myasthenia gravis: A clinicalimmunological update. J Neurol. 2016;263(4):826-34. [PubMed: 26705120].

[8] Huijbers MG, Lipka AF, Plomp JJ, Niks EH, van der Maarel SM, Verschuuren JJ. Pathogenic immune mechanisms at the neuromuscular synapse: The role of specific antibody-binding epitopes in myasthenia gravis. J Intern Med. 2014;275(1):12-26. [PubMed: 24215230].

[9] Gallardo E, Martinez-Hernandez E, Titulaer MJ, Huijbers MG, Martinez MA, Ramos A, et al. Cortactin autoantibodies in myasthenia gravis. Autoimmun Rev. 2014;13(10):1003-7. [PubMed: 25193850].

[10] Higuchi O, Hamuro J, Motomura M, Yamanashi Y. Autoantibodies to low-density lipoprotein receptor-related protein 4 in myasthenia gravis. Ann Neurol. 2011;69(2):418-22. [PubMed: 21387385].

[11] Hoch W, McConville J, Helms S, Newsom-Davis J, Melms A, Vincent A. Auto-antibodies to the receptor tyrosine kinase MuSK in patients with myasthenia gravis without acetylcholine receptor antibodies. Nat Med. 2001;7(3):365-8. [PubMed: 11231638].

[12] Pevzner A, Schoser B, Peters K, Cosma NC, Karakatsani A, Schalke B, et al. Anti-LRP4 autoantibodies in AChRand MuSK-antibody-negative myasthenia gravis. J Neurol. 2012;259(3):427-35. [PubMed: 21814823].

[13] Rivner MH, Pasnoor M, Dimachkie MM, Barohn RJ, Mei L. Muscle-specific tyrosine kinase and myasthenia gravis owing to other antibodies. Neurol Clin. 2018;36(2):293-310. [PubMed: 29655451].

[14] Chamberlain JL, Huda S, Whittam DH, Matiello M, Morgan BP, Jacob A. Role of complement and potential of complement inhibitors in myasthenia gravis and neuromyelitis optica spectrum disorders: A brief review. J Neurol. 2019 Sep 3. doi: 10.1007/s00415-019-09498-4. [Epub ahead of print]. Erratum in: J Neurol. 2019 Oct 17. doi: 10.1007/s00415-019-09568-7. [Epub ahead of print]. [PubMed: 31482201].

[15] Howard JF, Jr. Myasthenia gravis: The role of complement at the neuromuscular junction. Ann N Y Acad Sci. 2018;1412(1):113-28. [PubMed: 29266249].

[16] Kusner LL, Kaminski HJ, Soltys J. Effect of complement and its regulation on myasthenia gravis pathogenesis. Expert Rev Clin Immunol. 2008;4(1):43-52. [PubMed: 20477586].

[17] Alexion Pharmaceuticals Inc. SOLIRIS ${ }^{\circledR}$ (Eculizumab) Injection Prescribing Information; 2019 [cited October 2019]. Available from: https://alexion.com/Documents/ Soliris_USPI.pdf.

[18] Alexion Europe. Soliris (Eculizumab) Summary of Product Charateristics; 2019 [cited October 2019]. Available from: https://www.ema.europa.eu/en/documents/productinformation/soliris-epar-product-information_en.pdf.

[19] Pharmaceuticals and Medical Devices Agency. Eculizumab (Genetical Recombination) SOLIRIS ${ }^{\circledR}$ for Intravenous Infusion 300mg (Japanese Package Insert), Revised: February 2019 (Version 11); 2019 [cited November 2019]. Available from: http://www.soliris.jp/common/ pdf/tempu_bunsho.pdf.

[20] Howard JF, Jr., Barohn RJ, Cutter GR, Freimer M, Juel VC, Mozaffar T, et al. A randomized, double-blind, placebocontrolled phase II study of eculizumab in patients with refractory generalized myasthenia gravis. Muscle Nerve. 2013;48(1):76-84. [PubMed: 23512355]. 
[21] Thomas TC, Rollins SA, Rother RP, Giannoni MA, Hartman SL, Elliott EA, et al. Inhibition of complement activity by humanized anti-C5 antibody and single-chain Fv. Mol Immunol. 1996;33(17-18):1389-401. [PubMed: 9171898].

[22] Wolfe GI, Herbelin L, Nations SP, Foster B, Bryan WW, Barohn RJ. Myasthenia gravis activities of daily living profile. Neurology. 1999;52(7):1487-9. [PubMed: 10227640].

[23] Barnett C, Katzberg H, Nabavi M, Bril V. The quantitative myasthenia gravis score: Comparison with clinical, electrophysiological, and laboratory markers. J Clin Neuromuscul Dis. 2012;13(4):201-5. [PubMed: 22622164].

[24] Elsheikh B, Arnold WD, Gharibshahi S, Reynolds J, Freimer M, Kissel JT. Correlation of single-breath count test and neck flexor muscle strength with spirometry in myasthenia gravis. Muscle Nerve. 2016;53(1):134-6. [PubMed: 26437790].

[25] Gajdos P, Tranchant C, Clair B, Bolgert F, Eymard B, Stojkovic $\mathrm{T}$, et al. Treatment of myasthenia gravis exacerbation with intravenous immunoglobulin: A randomized doubleblind clinical trial. Arch Neurol. 2005;62(11):1689-93. [PubMed: 16286541].

[26] Muppidi S, Wolfe GI, Conaway M, Burns TM. MGADL: Still a relevant outcome measure. Muscle Nerve. 2011;44(5):727-31. [PubMed: 22006686].

[27] Sieb JP. Myasthenia gravis: An update for the clinician. Clin Exp Immunol. 2014;175(3):408-18. [PubMed: 24117026].

[28] Jowcar A. Myasthenia gravis medication; 2018 [cited October 2019]. Available from: https://emedicine.medscape. com/article/1171206-medication.

[29] Howard JF, Jr, Utsugisawa K, Benatar M, Murai H, Barohn RJ, Illa I, et al. Safety and efficacy of eculizumab in anti-acetylcholine receptor antibody-positive refractory generalised myasthenia gravis (REGAIN): A phase 3, randomised, double-blind, placebo-controlled, multicentre study. Lancet Neurol. 2017;16(12):976-86. [PubMed: 29066163].

[30] Mantegazza R, Cordiglieri C, Consonni A, Baggi F. Animal models of myasthenia gravis: Utility and limitations. Int $\mathbf{J}$ Gen Med. 2016;9:53-64. [PubMed: 27019601].

[31] Morgan BP. The membrane attack complex as an inflammatory trigger. Immunobiology. 2016;221(6):747-51. [PubMed: 25956457].

[32] Leite MI, Jacob S, Viegas S, Cossins J, Clover L, Morgan BP, et al. IgG1 antibodies to acetylcholine receptors in 'seronegative’ myasthenia gravis. Brain. 2008;131(Pt 7):1940-52. [PubMed: 18515870].

[33] Leite MI, Strobel P, Jones M, Micklem K, Moritz R, Gold R, et al. Fewer thymic changes in MuSK antibodypositive than in MuSK antibody-negative MG. Ann Neurol. 2005;57(3):444-8. [PubMed: 15732104].
[34] Leite MI, Waters P, Vincent A. Diagnostic use of autoantibodies in myasthenia gravis. Autoimmunity. 2010;43(56):371-9. [PubMed: 20380582].

[35] Vincent A, Huda S, Cao M, Cetin H, Koneczny I, Rodriguez Cruz PM, et al. Serological and experimental studies in different forms of myasthenia gravis. Ann N Y Acad Sci. 2018;1413(1):143-53. [PubMed: 29377162].

[36] Cossins J, Belaya K, Zoltowska K, Koneczny I, Maxwell S, Jacobson L, et al. The search for new antigenic targets in myasthenia gravis. Ann N Y Acad Sci. 2012;1275:123-8. [PubMed: 23278587].

[37] Jacob S, Viegas S, Leite MI, Webster R, Cossins J, Kennett $\mathrm{R}$, et al. Presence and pathogenic relevance of antibodies to clustered acetylcholine receptor in ocular and generalized myasthenia gravis. Arch Neurol. 2012;69(8):994-1001. [PubMed: 22689047].

[38] Vincent A, Leite MI, Farrugia ME, Jacob S, Viegas S, Shiraishi $\mathrm{H}$, et al. Myasthenia gravis seronegative for acetylcholine receptor antibodies. Ann N Y Acad Sci. 2008;1132:84-92. [PubMed: 18567857].

[39] Shiraishi H, Motomura M, Yoshimura T, Fukudome T, Fukuda T, Nakao Y, et al. Acetylcholine receptors loss and postsynaptic damage in MuSK antibody-positive myasthenia gravis. Ann Neurol. 2005;57(2):289-93. [PubMed: $15668981]$.

[40] Hoffmann S, Harms L, Schuelke M, Rückert JC, Goebel $\mathrm{HH}$, et al. Complement deposition at the neuromuscular junction in seronegative myasthenia gravis. Acta Neuropathol. 2020 Mar 10 [Epub ahead of print]. [PubMed: 32157386]

[41] Huijbers MG, Zhang W, Klooster R, Niks EH, Friese MB, et al. MuSK IgG4 autoantibodies cause myasthenia gravis by inhibiting binding between MuSK and Lrp4. Proc Natl Acad Sci U S A. 2013;110(51):20783-8. [PubMed: 24297891].

[42] Sanders DB, Wolfe GI, Benatar M, Evoli A, Gilhus NE, Illa I, et al. International consensus guidance for management of myasthenia gravis: Executive summary. Neurology. 2016;87(4):419-25. [PubMed: 27358333].

[43] Hillmen P, Young NS, Schubert J, Brodsky RA, Socie $\mathrm{G}$, Muus $\mathrm{P}$, et al. The complement inhibitor eculizumab in paroxysmal nocturnal hemoglobinuria. N Engl J Med. 2006;355(12):1233-43. [PubMed: 16990386].

[44] Zuber J, Fakhouri F, Roumenina LT, Loirat C, FremeauxBacchi V. Use of eculizumab for atypical haemolytic uraemic syndrome and C3 glomerulopathies. Nat Rev Nephrol. 2012;8(11):643-57. [PubMed: 23026949].

[45] Zuber J, Le Quintrec M, Krid S, Bertoye C, Gueutin V, Lahoche A, et al. Eculizumab for atypical hemolytic uremic syndrome recurrence in renal transplantation. Am $\mathbf{J}$ Transplant. 2012;12(12):3337-54. [PubMed: 22958221].

[46] Dhillon S. Eculizumab: A review in generalized myasthenia gravis. Drugs. 2018;78(3):367-76. [PubMed: 29435915]. 